\title{
The Effect of Centrifugal Force upon the Cell.
}

\author{
BY \\ DAVID M. MOTTIER, \\ Professor of Botany in Indiana University, Bloomington, Ind., U. S. A.
}

With Plate XVIII.

$\mathrm{HE}$ subject discussed in the following pages is one which
has received little or no attention at the hands of either the botanist or zoologist. So far as is known to the writer there exists, as yet, no published account of any extended study dealing primarily with the effect of centrifugal force upon the living contents of the cell. It is true that centrifugal force has been extensively used by investigators in studies on geotropism, but in almost every case the reaction of the plant as a whole, or of its organs, was the primary object of research. This has also been largely the point of view of the experimental morphologist in dealing with animals.

Dehnecke ('80) has observed that, in cells of the starchsheath of Impatiens, the large starch-grains, or clusters of them, would fall to the lower end of the cell by virtue of their own weight. This fact may be very readily verified by observing, with the microscope, cells of the starch-sheath of the plant in question held in a vertical position.

[Annals of Botany, Vol. XIII. No. LI. September, I899.] 
Dehnecke states also that, when the plant is revolved slowly in a horizontal position upon the klinostat, the starchgrains will fall from one edge of the cell to the other, and may thus be made to glide round within the cell in a plane parallel to the transverse axis.

It is evident, a priori, that the heavier inclusions of the protoplasm may be made to fall toward any side of the cell by means of centrifugal force. It was the purpose of the writer to determine, at least in a general way, what parts of the living substance and its inclusions could be displaced within the cell by means of a centrifugal force several hundredfold greater than that of gravity acting for certain definite but usually short periods of time, and to see what effect such displacement might have upon the individual cell.

The results in many cases were surprising, and may prove to be of considerable theoretical importance, so that a somewhat detailed discussion will, no doubt, be of interest to the botanist, and especially to the experimental cytologist, whether his object of investigation be the plant or animal cell.

Various Algae, leaves of Mosses, of Elodea and Vallisneria, together with trichomes and seedlings of several Phanerogams, furnished material for investigation. Of the Algae those most easily procurable at the time were selected, such as Cladophora, Spirogyra, Oedogonium, Vaucheria, Mesocarpus, Chara and Nitella. Trichomes of Urtica, Momordica, Cucurbita, Primula, with many others; stamen-hairs of Tradescantia, leaves of Funaria and Elodea, and sections from leaves of Vallisneria, together with seedlings of Zea Mays, Vicia Faba, Ricimus, Phaseolus, \&c., were also found suitable for experimentation.

A centrifugal force varying from 1700 to I930 times that of gravity was generated by the use of an ordinary milk-centrifuge driven by a gas-motor.

The objects selected for study were placed in strong glass cylinders, which were securely packed in the drum of the centrifugal machine. The drum permitted of a slight variation in the length of the radius, so that by moving the cylinders toward or from the centre a considerable difference 
in intensity of the centrifugal force could be obtained without varying the speed of the motor ${ }^{1}$.

\section{Cladophora.}

As Cladophora proved to be a suitable object for these experiments, and since the results in many respects were strikingly interesting and instructive, a detailed account of the behaviour of this plant may serve as an introduction to what follows, and also to give some idea of the phenomena discussed.

Fresh growing specimens, with tolerably large cells, were always selected for study.

Pieces of filaments about 2 or $2 \frac{1}{2}$ centimetres long were fastened upon a slide under a cover-glass by means of gypsum. One end of the filaments only is enclosed in an edge of the cast so made that this edge projects a short distance under one side of the cover-glass and overlapping the latter to the same extent. By means of sealing-wax, small grains of sand were first glued to the opposite corners of that edge of the cover-glass enclosed in the cast : in this way the cover-glass is held firmly and steadily in the same position. A larger grain of sand is similarly glued to the slide over which the cast is made in order to prevent any movement of the latter from side to side, and a small rubber-band holds cast and slide securely together. The preparations thus constructed are packed securely in the cylinders with cotton, and enough water is added to cover the specimens.

This method of preparation permits direct observation immediately upon removing the specimens from the centrifugal machine, and at any subsequent time.

1 The centrifugal force may be calculated according to the following formulae:

$\frac{4 \pi R \text { (in metres) }}{g t^{2}}, \frac{4 \pi^{2}}{g}=4.024$, a constant.

$4.024 \times \frac{R}{t^{2}}=$ no. of $g$ (gravity).

$R=$ radius expressed in metres.

$t=$ time in seconds of one revolution of the drum. 
In order to observe the behaviour of the cells from time to time after the application of centrifugal force, the preparations were kept in a moist chamber; and, when the plants operated with were Algae, one end of the slide was allowed to dip into the water. The water was renewed every day or two to prevent the accumulation of bacteria and other foreign organisms. From time to time a small quantity of gypsum was thrown into the water of the moist chamber or small aquarium to prevent a too rapid dissolution of the gypsum casts, and as it was found that the Algae thrived better in the dilute gypsum-solution than in the tap-water alone.

For the most part the centrifugal force was allowed to act parallel to the longitudinal axis of the cell ; but also frequently, for the sake of comparison, in an oblique and transverse direction.

We shall direct our attention first to the effect of centrifugal force acting longitudinally.

Specimens of Cladophora were subjected for about one hour and a half to a centrifugal force varying from I 700 to I $800 \mathrm{~g}$.

The time necessary to bring about the desired displacement when the force remains constant varied with the size of the cell and the nature of the contents.

In cells of Cladophora, with the proportional dimensions of Figs. I and 2, immediate observation after centrifugal action showed that almost the entire contents were crowded into a dense mass at the end of the cell. Apart from an occasional chloroplast and sometimes a nucleus, nothing of the living substance or its inclusions remains undisturbed except the ectoplasm or hautschicht and the plasmic lamellae which penetrate the cavity of the cell and divide it into a number of irregular polygonal chambers varying much in size (Figs. $I$ and 2).

Seen with the low power of the microscope, each cell appears perfectly colourless with a dense dark-green mass at one end. In all probability the lamellae always remain stationary or nearly so, and the chloroplasts and nuclei fall 
through them, just as a small glass bead may be made to fall through a column of soap-foam.

As the lamellae are laid bare by means of the centrifugal force, thus enabling an unobstructed view of the interior of the cell, a word further as regards its structure may not be out of place here.

As is well known (Strasburger, '97), these lamellae may be distinguished in normal cells of Cladophora not too rich in chlorophyll. Upon them are usually distributed nuclei and chloroplasts. When the movable cell-contents are removed, the lamellae appear rigid, forming sharp angles with each other like so many cell-walls; in fact the cell looks as if it were filled with a thin-walled parenchymatous tissue. The lamellae shift their position little or not at all. On careful observation with high powers or oil-immersion, they are seen to be in a constant vibrating or quivering motion, and over their surface a thin layer of colourless cytoplasm is seen to move. It cannot be unreservedly stated that the lamellae quiver or vibrate constantly, but this movement was seen at each observation.

Immediately the preparation is taken from the centrifugal machine, the displaced contents begin to redistribute themselves, but, in Cladophora especially, very slowly, requiring often three weeks for a complete redistribution. During the first twenty-four hours the redistribution takes place more rapidly, after which it becomes slower and more uniform. The time of redistribution will vary with the size of the cell, being less in small narrow cells.

Fig. I was drawn twenty-four hours after the centrifugal action, when a portion of the chlorophyll and other inclusions had advanced somewhat into the colourless part of the cell. In the beginning all the movable contents occupied the space indicated by the densely shaded portion of the cell. As a rule the chloroplasts, and presumably the nuclei also, travel back toward the opposite end in a tolerably uniform layer, only a few isolated chloroplasts proceeding faster. The plastids and nuclei, together with the more coarsely granular 
colourless cytoplasm, retreat partly along the ectoplasm and partly upon the lamellae.

It may be mentioned, however, that as soon as observation is possible after centrifugal action an active streaming of a thin layer of cytoplasm is to be seen upon the lamellae and along the hautschicht. This is true in all cells of the various plants observed at the time in question; the movement is, of course, toward the end of the cell from which the contents were made to fall.

Although, as previously mentioned, the retreating contents proceed in a tolerably uniform layer, yet this layer does not contain as many chloroplasts and nuclei as were originally distributed over the same area of the cell. Many of these bodies travel more slowly than others; for when the retreating layer or mass reaches the opposite end of the cell this end presents a light, pale-green colour which passes over gradually into the deep green of the other end into which the contents were thrown.

A noteworthy phenomenon presents itself in cells that were undergoing division at the time of centrifugal action. If the ring-shaped membrane were narrow, the contents of one daughter-cell would be forced through into the opposite end of the other, just as if no cellulose-ring were present (Fig. 2). If, however, the forming transverse wall had proceeded to such an extent that the circular opening remaining was only one-third or one-half the diameter of the cell, a few chloroplasts were generally lodged against the new wall. This was often the case in Spirogyra, to be mentioned later, where often an end or fold of some chlorophyll-band caught against the ring-shaped membrane. When, on the contrary, the opening remaining in the membrane was smaller, in large cells less than one-half the diameter, the chlorophyll-grains were not forced through.

During redistribution of the displaced contents in such cells, as just mentioned, the retreating mass creeps back through the opening in the incomplete transverse membrane, and becomes equally distributed as under ordinary circumstances. 
When the opening is equal to about one-half the transverse diameter of the cell or a little less, the progress of the retreating contents is greatly retarded, but finally a portion succeeds in passing through and distributing itself in that portion of the cell.

Transverse walls which were being formed at the time of centrifugal action were never completed. Several instances were closely observed from day to day for three consecutive weeks, during which time the contents had become uniformly redistributed; but the cellulose-ring remained unchanged, except undergoing secondary thickening by the apposition of new layers in common with the entire wall of the cell.

This fact seems to indicate clearly that, when the relation existing between the transverse wall in process of formation and the nuclei and movable cytoplasm connected therewith is once destroyed, it is not restored again so as to complete the cell-wall. It was observed also that later some of these - cells in question divided, and the division-wall was laid down near the old cellulose-ring. We shall return to this phase of the subject in a subsequent paragraph.

As already stated, a violent displacement of all movable contents in cells of Cladophora does not interfere materially with cell-growth or division, for a day or two after centrifugal action it was not at all uncommon to find cells dividing whose displaced contents had only fairly begun to redistribute themselves (Fig. 3). This fact may throw some light upon the relation of the amount of cytoplasm to cell-division. From Fig. 3 it will be seen that the resulting daughter-cells are of unequal size. The smaller presents a striking contrast in size and colour to the larger, which contains only a relatively small number of chloroplasts. Very often three or more such cells were to be seen in a piece of filament one and a half centimetres long. The entire process of division was followed in several cases, so that there can be no doubt as to the accuracy of the statement. So far as determined the number of nuclei was less in the longer cell (Fig. $3, b$ ), but whether the quantity of cytoplasm is proportional could not be ascertained. 
In the longer daughter-cell ( $b$, Fig. 3 ), the chlorophyllgrains finally became uniformly distributed, when such cells from their pale-green colour form a striking contrast to the deep green of their neighbours, especially their sister-cells. So far as observation extended, subsequent growth in length seemed to be the same in both cells, i.e., the shorter did not increase in length more rapidly than the longer. In the larger cells, such as b, Fig. 3, with fewer chloroplasts, these bodies multiplied so that after a time the amount of chlorophyll in the cell was appreciably increased. For lack of time the ultimate fate of these cells could not be followed.

Centrifugal force acting transversely, i.e. at right angles to the longitudinal axis of the cell, caused the contents to collect into a band-shaped mass along the opposite side.

After transverse displacement, redistribution required a relatively short time, the distance to be traversed by the displaced constituents being much shorter.

\section{SPIROGYRA.}

Spirogyra, being in many respects a less hardy plant than Cladophora, is more susceptible to injury from violent centrifugal action. Specimens with tolerably large cells containing only one or two chlorophyll-bands were found suitable for experimentation. Subjected to the centrifugal action for the same length of time as Cladophora, a relatively large number of cells were badly injured, while many were killed outright. Consequently the time was shortened to periods of less than one hour. For the specimens operated with, three-fourths of an hour were sufficient to effect a complete longitudinal displacement of all movable contents of the cell. The cells to which the following paragraph refers contained but two chlorophyll-bands with abundant starch clustered about the pyrenoids. The specimens were fresh and actively growing with many of the cells in process of division.

Fig. 4 represents a cell drawn immediately the preparation 
was removed from the centrifuge. It had been subjected for three-fourths of an hour to a force of $1820 \mathrm{~g}$. All the movable contents were heaped up in the end of the cell. As soon as observation is possible after the cessation of centrifugal action (it required about five minutes to stop the machinery and remove the preparations), an active streaming movement toward the opposite end of the cell is seen in very finely granular cytoplasmic strands extending along the hautschicht. These strands generally anastomose. Not infrequently, and in very large cells especially, a cytoplasmic band is formed which encircles the cell in an exactly transverse direction. Movement within such a band follows the direction of the same. With the gradual redistribution of the cell-contents these bands, when present, progress uniformly in front of the chloroplasts.

About twenty or twenty-four hours after centrifugal action, a thicker layer of fine granular cytoplasm is distributed over the entire surface of the hautschicht (Fig. 5) i.e., the primordial utricle is now thicker. It is also to be seen (Fig. 5) that the chlorophyll-bands, together with the nucleus suspended by cytoplasmic strands which extend apparently from the pyrenoids, have begun to creep back to resume their position in the cell. It often happens, however, that the bands do not stretch out evenly, contiguous edges often adhering so as to give the bands a tangled appearance. This is generally true when a larger number of bands with steep turns are present in the cell. In such cases a longer time is necessary for an even and complete redistribution. Whenever only two or three bands are present, distribution is quite uniform and regular (Fig. 6).

In cells such as represented in Figs. 5 and 6 , a complete redistribution may take place in seven or eight days, perhaps sooner, but often fifteen to eighteen, and even more, are necessary.

The rapidity with which redistribution takes place, as will be seen later, depends to some extent upon the temperature and perhaps illumination. In many instances when redis- 
tribution was complete, there was nothing to indicate in any way that either bands or nucleus had experienced any change in position in the cell. The nucleus did not always resume an exactly central position in the cell; sometimes it would not quite reach the centre, or it might pass a short distance beyond it.

As in Cladophora, cells sometimes divided before a complete redistribution of the contents was accomplished, when the daughter-cells varied greatly in length, being to each other as $\mathrm{I}: 3$. In the shorter cell the chlorophyll-bands necessarily remained crowded closely together, giving the cell a dark-green colour; in the longer, the relatively shorter pieces of bands stretched themselves the entire length of the cell, making not more than one and a half transverse turns. The nuclei always took up a central position in their respective cells.

Centrifugal force acting transversely upon the cells of Spirogyra often seriously affected their vitality, in fact killing many outright. As a rule a longer time was found necessary to effect a complete transverse displacement of the chlorophyllbands. In large cells whose several bands wound at a sharp angle, these are usually broken at the side of the cell from which they are removed. In passing over to the opposite or ' lower side ${ }^{1}$ ' of the cell, one free end of each severed portion moves along in the primordial utricle upon one side parallel to the direction of centrifugal force, and the other upon the other side. Everything seemed to indicate that the ends arising from the severing of the bands did not move through the vacuole. In rather long and slender cells, however, with only few bands making long turns, the bands are not severed, and it seems that the displaced portion passes directly through the central cavity or vacuole.

Whenever the bands were broken at several points, the cell was so injured that death resulted soon after centrifugal action. It often happened that only a partial displacement

1 By 'lower side' or 'lower end' is meant that against which or into which the contents are accumulated by the centrifugal force. 
of the chlorophyll-bands was brought about, which consisted in a mere bending away of the displaced parts from the cellwall. Under such circumstances recovery took place in one night. A redistribution of transversely displaced contents is accomplished in a relatively short time, especially in slender cells with few chlorophyll-bands which have not suffered appreciable injury.

As in Cladophora, the most interesting phase of the subject presented itself in the behaviour of those cells undergoing division at the time of the experiment. Material exhibiting dividing cells was obtained by placing the vessels containing fresh growing specimens on ice over night, and removing them the following morning to the temperature of the room (about $20^{\circ} \mathrm{C}$.). During a larger part of the day dividing cells may be found without difficulty in material thus treated.

In dividing cells, the contents of one were forced through the circular opening in the transverse wall in process of formation provided that this opening was not less than one third or two-fifths the diameter of the cell. An end of a chlorophyll-band not infrequently caught against the edge of the partly formed membrane, when that end or portion remained in the otherwise perfectly colourless daughter-cell. In any case the bands on redistributing themselves began to creep back through the opening into the colourless cell. In Spirogyra, however, the redistribution of the cell-contents was never effected so regularly when a partly formed cellwall interposed, and it could not be determined definitely whether the displaced daughter-nucleus returned to its cell. In Mesocarpus, where distribution is easier on account of the single straight chlorophyll-band, it was seen that the nucleus passed back with the chlorophyll-band into the colourless cell. In all such cases, division had not progressed far enough to sever the chloroplast. As in Cladophora, neither in Spirogyra nor in Mesocarpus was the transverse wall ever completed after its original connexion with the nuclei had been disturbed.

So far as known, cell-division in Cladophora stands in no 
direct connexion with nuclear division, while in Spirogyra and Mesocarpus both processes take place at the same time, although the transverse walls seem to be laid down in the same way in each plant; that is, the membrane begins at the hautschicht and is developed inwards. The more intimate relation existing between the nuclei and these types of cellwall formation, which may be designated as the Cladophora and Spirogyra types respectively, is virtually unknown notwithstanding the fact that both plants have become classical as objects of investigation.

Gerasimoff ('97) has shown that, when dividing cells of Spirogyra and Zygnema are exposed to a temperature below $0^{\circ} \mathrm{C}$., the process of division is inhibited, and one of the daughter-nuclei may pass over into the other cell, thereby giving rise to an enucleated cell-chamber and one with two nuclei. He found also that similar results could be brought about by means of certain anaesthetics.

A similar behaviour was observed in the course of my own studies upon Spirogyra. As previously stated, the plants were kept on ice over night, but the temperature never fell below $0^{\circ} \mathrm{C}$. As a rule, the temperature of the water containing the plants when the vessels were removed from the refrigerator on the following morning was $3^{\circ}$ or $5^{\circ} \mathrm{C}$.

In several cases observed, one of the nuclei moved back into the enucleated cell in four or five days after the experiment, but the ring-shaped transverse wall never developed further. Plasmic cords extended through the opening in the wall from one cell to the other. Other cases were noticed where both nuclei remained in the same cell-cavity, when one of them, and apparently that which had left its cell, became partly cut off from the rest of the cell by an irregularlyshaped membrane. For lack of time, a further study of this phase of the subject was impossible.

As regards the type of cell-wall formation displayed in the vegetative division of cells of Cladophora, Spirogyra, Zygnema and Mesocarpus, it may be safely stated that, when the relation existing between a cell-wall in process of formation and the 
nuclei concerned therewith is violently disturbed, the completion of the cell-wall as such does not take place.

\section{Stamen-Hairs of Tradescantia.}

The behaviour of cells of the stamen-hairs of Tradescantia in response to violent centrifugal force proved to be of much comparative interest. These cells lend themselves readily to this as well as to many other sorts of experimentation.

By means of gypsum, young unopened buds were fastened in short pieces of glass-tubing just large enough in diameter to admit them. The tubes were then packed in the cylinders previously mentioned. After centrifugal action, the buds were removed from the tubes and kept upon wet filter-paper in a moist chamber where they remained fresh for two or more days, during which time the cells of the stamen-hairs divided as usual. For immediate observation after centrifugal action, a bud is opened and the stamen transferred to a slide. Fastening individual stamens or even sections through the bud upon the slide proved not only difficult and troublesome but also more or less injurious to the cells.

With buds arranged in this way, the line of centrifugal force was coincident with the longitudinal axis of the majority of the hairs, while many others lay at various angles to the same, making possible a displacement in all directions in the same bud.

We shall direct our attention first to cells still in the embryonic condition, i.e. capable of division. In all the younger cells of the hair, the nucleus, together with the movable cytoplasm and its inclusions, was forced into a dense mass in the lower end of the cell, while the vacuole or vacuoles were compelled to occupy the opposite end or half of the cell. In a short time after the cessation of centrifugal force a normal redistribution was effected.

In any stage of karyokinesis between that of the spindleand the telo-phase, the figure is often forced into an oblique position in the cell, and the arrangement of the chromosomes 
somewhat distorted. A distortion of the figure is, however, not the rule in Tradescantia, but slight distortions may be often present which are invisible in the living cell.

In Fig. 7 is shown a cell with dividing nucleus, in which the straight or slightly curved rod-shaped chromosomes have arrived at the poles. Each set of chromosomes is inclined slightly to the longitudinal axis of the spindle. Judging from this figure, it seems that the spindle-fibres extending from pole to pole offer some resistance to the weight of the chromosomes of the one daughter-nucleus which tend to fall into the end of the cell upon those of the other daughter-nucleus. In no case observed were the chromosomes at one pole thrown over upon those at the other. The chromosomes (Fig. 7) did not orient themselves again so that their long axes might coincide with that of the cell, but formed at once the daughterspirem by the union of their respective adjacent ends. It must not be forgotten, however, that only a few of the finer details of the karyokinetic figure can be seen in the living plant-cell even in the most favourable cases. The spindlefibres in the cell shown in Fig. 7 could be seen only faintly, the displaced cytoplasm in which the karyokinetic figure lay rendering the view less clear than under ordinary conditions, so that a more accurate knowledge of detail must await investigation by the indirect method. The division-wall resulting from this division (Fig. 7) was only slightly oblique. Its formation, which was observed continually, took place in about the same time as in cells not exposed to centrifugal action.

Fig. $9 a-g$ will serve to illustrate the process of cell-division immediately following a transverse displacement of the contents. The protoplasm capable of being moved by the centrifugal force was merely collected along one side of the cell, thus suffering displacement through a relatively short distance. When first observed the nucleus was in the anaphase (Fig. 9 $\alpha$ ). The cell-plate is soon laid down within the connecting fibres and in contact with the cell-wall upon one side (Fig. $9 b$ ). The connecting fibres gradually bulge out at the equator, forming the familiar barrel-shaped system. The bending out 
is, of course, more pronounced on the side next to the vacuole (Fig. $9, c$ to $g$ ). The cytoplasmic strands running from the plasmic mass to the hautschicht change position, while additional ones appear. The growth of the cell-plate (Mottier '97) keeps pace with the diametrical increase of the system of connecting fibres at the equator, so that when the latter reaches the opposite wall a transverse membrane is formed and cell-division is complete. The increase in diameter of the system of connecting fibres is accompanied by a shortening of its length, so that when the cell-plate is formed the daughter-nuclei come to lie close to it. In a short time now the entire contents of each cell assume their normal orientation. The processes embraced by $a$ and $f$, Fig. 9, required forty minutes; between $f$ and $g$, eight minutes.

A division of the cell often takes place before the nucleus regains its more central position, displacement having been longitudinal. The result of such a division is shown in Fig. 8, in which the daughter-cells are of unequal size. This figure was drawn twenty-four hours after displacement. In this case it is not known whether or not the cell was in division at the time of centrifugal action; but other instances were observed in which both nucleus and cell divided while the former lay in the end of the cell. It is doubtful whether nuclear or cell-division can continue during the action of centrifugal force as great as that used, for the phenomena observed immediately afterwards seemed to indicate clearly that the karyokinetic process is inhibited. No special effort was made to determine whether the process is accelerated or retarded as a result of centrifugal action. The time required for the completion of that part of the process illustrated in Fig. 9 was nearly the same as for corresponding phases under ordinary conditions. The difference, if there be any, is certainly small, whether on the side of acceleration or retardation.

These observations seem to indicate further that, where the cell-wall is laid down through the direct instrumentality of the kinoplasmic connecting fibres, its position in the cell is 
determined by that of the nuclei, while the proportional distribution of cytoplasm plays a secondary and minor part as a factor in regulating the division or size of the resulting daughter-cells.

The results of centrifugal action upon older cells of the stamen-hairs, i. e., those no longer capable of dividing, and whose rôle is purely vegetative in character, proved to be interesting, though of much less theoretical importance. A relatively longer time was necessary to effect the desired displacement than in those still in the embryonic condition. The following remarks apply more particularly to cells in which the cell-sap had become only slightly or not at all coloured. In mature cells the coloured cell-sap and the nature of the cell-wall interfered with a distinct view of the living contents.

In cells where a displacement of a larger part of the contents was effected, the nucleus, much cytoplasm, and all the larger inclusions, were massed in the lower end of the cell, the vacuoles occupying the remaining and larger part of the cell-cavity. The cytoplasmic strands which penetrate the cavity of the cell, or at least some of them, remained in position. As soon as observation was possible, an active streaming towards the lower end of the cell was seen in the strands, showing that the displaced cytoplasm had begun to redistribute itself rapidly. The larger inclusions also began to move, and in a short time they were normally distributed in the cytoplasm. The nucleus is often slow to move from its centrifugal position. Sometimes it may regain a position midway between the ends of the cell, shifting the same from time to time as under ordinary circumstances; then again it may remain almost stationary in the displaced position.

\section{OTHER TRICHOMES.}

Observations upon various other trichomes, although furnishing data of much less interest than those of Tradescantia, may not nevertheless be wholly without significance. Trichomes 
of a large number of Phanerogamic species from widely different families were used, with results varying only in minor details. Those of Urtica, Momordica and Cucurbita, which seemed more favourable for this study, merit some special mention.

Sections of the leaf or petiole bearing hairs of suitable age were fastened upon the slide under a cover-glass in the same way as the algal filaments. Hairs of Urtica and Momordica are quite hardy, the cells living often for a week or ten days after subjection to a centrifugal force of $1820 \mathrm{~g}$ for one and a half to two hours; though of course there are always cells that seem to be seriously injured or killed outright either by handling or by the centrifugal action.

The cell-contents of hairs of Momordica possess about the same orientation as in Tradescantia, except perhaps that a greater number of plasmic strands traverse the cell-cavity or vacuole.

Centrifugal action lasting for one hour and a half displaces nucleus, chloroplasts, and much of the cytoplasm with all conspicuous inclusions, massing them in the lower end of the cell. As in Tradescantia, a number of the larger plasmic strands persist. The streaming movement of the cytoplasm may not have been entirely stopped by the action of the centrifugal force, for it was seen immediately the preparation was taken from the centrifugal machine, which required from five to seven minutes. It is possible, however, that the movement may begin again within that time.

The contents of the cells redistribute themselves in a relatively short time, usually less than twenty-four hours. It sometimes happens that a portion of the cell-contents consisting of dead or inert particles will remain in the lower end of the cell separate, and perhaps entirely cut off, from the actively circulating cytoplasm.

In the long pointed hairs of Urtica, when the contents are forced into the attenuated end of the cell, the nucleus especially, which seems wedged in between the walls, finds more difficulty in extricating itself. At the end of centrifugal 
action the displaced cytoplasm, including the nucleus, apparently fills the narrow tapering cavity for about one-half the length of the hair, except the small knob-like termination which still contains, in many cases at least, a vacuole. Although the tapering end seemed quite densely filled with cytoplasm and the nucleus was compressed into the form of an ellipse, yet a constant movement was kept up in the cytoplasm, passing into the point of the hair on one side of the nucleus and returning on the other. A rotating stream passed through the narrow neck into the knob on one side and returned along the other. In the broad basal portion of the cell in question, the rotation passed over gradually into the so-called streaming or circulating movement.

Twenty-four hours after centrifugal action, the cytoplasm was in a large part normally distributed. The nucleus in some cases remained for several days in the displaced position ; in others it wandered back into the broad basal part of the cell, its usual position. After a week the cells of the hairs in question were perfectly healthy, the cytoplasm exhibiting an active movement. In a few cases the same trichomes of Momordica and Urtica were subjected a second time to centrifugal action, with similar results.

In many trichomes a much longer duration of the centrifugal action is necessary to displace the living contents as described, especially where the primordial utricle is very thin and fewer heavy inclusions are present. Primula chinensis possesses this sort of trichome. Those operated with were taken from the petiole of young leaves. The cells contain a few pale and scattered chloroplasts, and a relatively small amount of cytoplasm with few of the more conspicuous granules. The delicate plasmic strands traverse the cell chiefly in a longitudinal direction. After five hours' exposure to a centrifugal force of $1820 \mathrm{~g}$, the nucleus, chloroplasts, and some of the finely granular cytoplasm, were found accumulated in the lower ends of the cells. On the next day all was normally distributed.

Hairs of Cucurbita obtained from seedlings were found to be 
more susceptible to injury than those of the other plants. Many seemed to have been killed outright while others died soon after centrifugal action.

FUNARIA.

Small, fresh specimens of Funaria were fastened upon a slide in the usual way. Individual leaves to be observed in detail after centrifugal action were then carefully removed from the plant and mounted in water. When such leaves were returned to the moist chamber to be kept for subsequent observation, the cover-glass was removed to allow free access of air. The behaviour of the cell-contents in leaves that had been removed from the plant was about the same as in those which were not detached.

The character of displacement varied in different parts of the leaf. In the longer and larger cells near the base, displacement was more easily brought about than in the smaller isodiametric ones of the terminal third or fourth of the leaf. Sometimes the contents in basal cells experienced a total displacement, while in those at the apex of the same leaf no perceptible change in the position of chloroplast or any other inclusion could be detected. Such leaves then presented a complete transition from cells in which all the contents capable of being displaced were made to fall into the lower end of the cell, to those in which no change in the position of any chloroplast was apparent.

The reason for this is unknown to the writer, unless it be due to the density or firmness of that part of the primordial utricle in which the chloroplasts are imbedded. According to all appearances the chloroplasts were about the same size with the same quantity of starch enclosed in each. If their specific gravity be less than that of those in the basal cells, no method of settling the question suggested itself at the time.

An average cell with displaced contents is shown in Fig. Io. It appears that the contents fill about one-half 
of the cell-cavity; but the side next to the vacuole is probably more concave than it seems, in which event the displaced mass would present the form of a cup. Delicate strands are frequently seen running along the hautschicht, from which ramifications may penetrate the cell-lumen. Displacement takes place in plasmolyzed cells very much as in normal ones (Fig. II). This fact would seem to indicate that the density of the cell-sap in itself does not affect in any appreciable way the free movement of bodies held in the cytoplasm. Cells may, of course, be plasmolyzed to such a degree that all the chloroplasts are crowded together, when little space is left for displacement and when the contracted primordial utricle holds all inclusions firmly in a fixed position.

In order to see what effect, if any, a difference in temperature and illumination might have upon the redistribution of the cell-contents, one set of plants on being removed from the centrifuge was placed in a cold house at a temperature of $2{ }^{\circ} \mathrm{C}$, while another was kept in the laboratory at a temperature varying from $16^{\circ}$ to $20^{\circ} \mathrm{C}$. Of those in the laboratory, one portion remained in diffused light, another was kept in darkness, and a third within a cylindrical screen of heavy white paper beneath an incandescent electric lamp. In cells exposed to the diffused light of the laboratory room at $20^{\circ} \mathrm{C}$., redistribution was about completed in four hours and a half. The chloroplasts were generally arranged along those cellwalls which are perpendicular to the surface of the leaf. In those kept in darkness at the same temperature $\left(20^{\circ} \mathrm{C}\right.$.), redistribution was accomplished in the same time, the orientation of the chloroplasts being the same. Redistribution in the cells exposed to the electric light required about the same time, but here the chloroplasts were more uniformly distributed upon the entire inner surface of the cell. Different intensities of illumination, therefore, so far as observation extended, played no important part as a factor in the redistribution.

Temperature, on the contrary, seemed to have much to do with the movement of displaced portions of the living substance 
and its inclusions. In cells exposed to a temperature of $2^{\circ} \mathrm{C}$ in the cold house, twelve to twenty hours were often required for a complete redistribution. The time varied, of course, in cells of different parts of the same leaf. In the smaller ones near the tip, where displacement is less easily brought about, recovery takes place more quickly under whatever conditions may prevail in which protoplasmic activity is possible.

\section{VALLISNERIA.}

Longitudinal sections of leaves were used for experimentation. Vallisneria proved to be a less favourable object for this study than the plants already mentioned. Even after a longer duration of centrifugal action, only a part of the chlorophyll was thrown into the lower end of the cell. On immediate examination after two hours of centrifugal action, a very decided movement was to be seen in many cells, both chloroplasts and starch-grains being carried along in the cytoplasmic stream. Many chloroplasts, - were, however, collected into larger and smaller clusters. Some of these clusters were thrown into the end of the cell, where they remained for a time, while others lay stationary along the sides of the cell. In a short time the chloroplasts became more evenly distributed, those aggregated into clusters separating from one another. It seemed that in these cells the movement of the protoplasm was not brought to a standstill by the centrifugal action. Soon after the preparations had been removed from the centrifuge, the protoplasm began to rotate in many cells in which no movement was perceived at first, and it is reasonable to suppose that the motion had been inhibited in such cells. Even in many cells in which no protoplasmic movement was noticeable when the experiment was begun, the chloroplasts were displaced in part only.

Since it seemed that the movement of the protoplasm interfered somewhat with the displacement of the cell-contents, an attempt was made to determine, if possible, in what measure the movement hindered the dislocation of the chloro- 
plasts and the inclusions. Consequently the movement was first inhibited by placing the sections, properly fastened upon a slide, in water containing from 3 to $5 \%$ ether. When all movement had ceased, the preparations were transferred to water containing just enough ether to prevent a return of the movement, in which they remained during centrifugal action. (It may be added here that when the movement had been stopped for several hours, the sections lying in ether-water all the while, it began again a few minutes after removal to fresh water.) In cells with the movement thus inhibited, more of the chlorophyll was made to fall into the lower end of the cell, but displacement was much less complete than was expected.

From this experiment it seems that there are other factors more potent in preventing a displacement of the cell-contents than the movement of the cytoplasm.

\section{Chara and Nitella.}

Chara and Nitella lend themselves much less readily to these experiments than the other plants investigated. As a rule the centrifugal force necessary to displace the chloroplasts which lie in the stationary part of the cytoplasm proved fatal. The cells are either killed outright, or retain their vitality for a short time only.

In order to bring about a complete displacement in certain cells only, it was necessary to continue the centrifugal action for five or six hours. It made no difference whether the rotation of the cytoplasm was first inhibited by ether or not. In Chara the results were different in different parts of the plant. In the uncorticated cells near the ends of the so-called leaves, displacement of the chlorophyll was effected in differen $t$ degrees. (Only terminal portions of good thrifty shoots about one centimetre and a half long were used.) Frequently much was removed from a tolerably broad strip on both sides of the neutral zone; then again this thinning out of the chloro- 
plasts is less localized, being generally more uniform throughout the cell.

In several instances rather striking phenomena presented themselves in uncorticated leaf-cells. In these, upon which the centrifugal force acted obliquely, almost the entire mass of chlorophyll was thrown into one corner of the cell, the remaining portion becoming thereby transparent. On the following morning, the specimens having been removed from the centrifuge at 6 p.m. of the day preceding, the mass of displaced contents remained in exactly the same position, apparently quite dead, while the colourless cytoplasm kept up a lively rotation. The living protoplasm of the cell had thus entirely separated itself from the displaced mass of chloroplasts and other granules. In the rotating protoplasm only a few chlorophyll-grains were present.

Other and similar cells of the same leaf were plasmolyzed and dead, while still others remained almost unchanged, i. e. no displacement was perceptible in them.

The cells of the whorl of undeveloped leaves closely enveloping the growing end of the shoot were virtually unchanged, no displacement having taken place except in the pointed distal cells which were killed.

Generally much of the contents was displaced in cells of the cortex. Here the chloroplasts and other bodies showed a tendency to distribute themselves, and sometimes this was in a large measure effected. Many cells died, however, as a result of the centrifugal force.

Displacement of the chlorophyll in the cortical cells often permitted to a large extent an unobstructed view of the interior of the large internodal cells of the leaves. In these cells, the chloroplasts and large colourless inclusions of the protoplasm were often thrown into the ends of the cells, filling them apparently for about one-fourth their entire length. In all such cases observed the displaced mass was dead on the following morning, and in many cells all other cell-contents as well.

In a few instances the colourless mass of protoplasm became 
segregated into two or more rounded portions, displaying a rapid rotating movement within. This segregation of the living contents is similar to certain phenomena of disorganization brought about by other external stimuli such as the action of electrical currents, \&c. (Klemm '95).

Again, whenever the displacement in the internodal cells was transverse instead of longitudinal, the displaced contents lay in a stationary band-shaped mass extending the entire length of the cell, while the colourless protoplasm enclosing the central vacuole kept up a constant rotation.

In both Chara and Nitella the centrifugal force almost always inhibited the movement of the protoplasm, which returned immediately the action ceased unless death ensued.

In Nitella displacement was less difficult. In every cell of the part of the plant used, the chlorophyll with the nuclei and other inclusions were crowded into a dense mass in the lower end of the cell ; but this sort of treatment proved too severe for Nitella, for every cell died before the chlorophyll began to distribute itself. If the centrifugal force were allowed to act only long enough to produce a partial displacement, the cells seemed uninjured, and the chloroplasts were soon redistributed.

\section{VAUCHERIA.}

From what has been said in the preceding pages in regard to the several plants mentioned, we know, a priori, about what to expect from a similar treatment of a majority of all plants.

In Vaucheria the presence of oil-bodies adds a new factor to our problem, and it is in this respect that this plant offers anything additional to what has thus far been considered. Centrifugal action of about one hour and a half was sufficient to drive nearly all or a vast majority of the chloroplasts into the ends of the filaments. (Pieces varying in length from one-half to one centimetre were used.) Those chloroplasts which remained behind seemed to be smaller and 
probably lighter than those displaced, or they may have been situated in a firmer part of the primordial utricle. Only a relatively small number of oil-globules are carried along with the chloroplasts; usually they lie scattered in the more proximal portion of the filament left colourless by the removal of the chlorophyll. They are, of course, most numerous just back of the chlorophyll. Consequently, the end of the filament presents a dark-green colour, which shades over gradually into the nearly colourless part from which the chlorophyll has been removed.

Certain large oil-globules, in which are included one or more chlorophyll-grains, are carried along with the displaced mass. These larger oil-bodies doubtless arise from a fusion of smaller ones and the chloroplasts lying in contact with them.

It sometimes happens that several such globules, together with other inclusions of the protoplasm, collect at certain points in the filament and form a sort of plug, which completely prevents further movement at these places, where the contents will then accumulate as in the end of the filament. In several instances it was observed that those parts of the filament which were clogged in this way became injured and were cut off from the main portions by transverse walls, just as when any part is injured by crushing or otherwise.

Twenty-four hours after displacement, considerable progress in the redistribution of the contents is noticeable, and in a few days there is nothing to indicate that any disturbance had taken place in those filaments which received no injury through clogging or otherwise. The oil-masses with their included chloroplasts redistribute themselves more slowly. Many of them soon disappear, probably by breaking up, thereby liberating the chloroplasts, when the oil doubtless takes part in the processes of metabolism; others, however, persist for a longer time.

A redistribution of the chloroplasts throughout the entire portion of the filament left nearly colourless by the displace- 
ment did not always take place, especially in longer pieces in which recovery was less rapid. The pieces of filaments almost invariably grew in length, thereby creating more space and a movement of the contents in the direction of growth. When such was the case, the proximal end of the filament remaining colourless would die after a time, and be cut off from the rest by a transverse membrane as in normal vegetative propagation.

It sometimes occurred that the ends of the filaments became thick and club-shaped, apparently as a result of the pressure exerted by the displaced contents. Further growth at such club-shaped ends manifested itself in a prolongation possessing the normal diameter of the filament, which sprang usually a little to one side of the middle point of the end.

Further experiments were made regarding the behaviour of oil-globules and bodies containing this substance in which leaves of certain Jungermanniaceae and root-tips of Ricimus were used.

In cells of the leaves of the Liverworts, some of the bodies containing oil were displaced along with the chloroplasts, but not so readily as the latter, while many others remained stationary. It will be remembered, however, that these bodies do not represent pure fatty oil but contain more or less proteid, which makes them heavier than pure oil.

Root-tips of Ricinus, having been subjected to the centrifugal force, were immediately fixed in a mixture of chromicosmic-acetic acid, imbedded in paraffin, and sectioned. The oil-globules are blackened by the osmic acid, so that they may be readily seen after the sections have been carefully stained and mounted in balsam. The proper combination of these acids must be used, or else the blackening may disappear, owing to oxidation caused by the action of the chromic acid.

Here the results were about what would be expected. The oil-bodies, being lighter, were completely separated from the other constituents of the cell. The nucleus, small starchgrains, and the bulk of the cytoplasm were accumulated in the 
distal end of the cell; while oil and the vacuole, whenever the latter was present, occupied the proximal end. The oil formed a dense layer along the proximal transverse wall, and when present in sufficient quantities it filled the space between the vacuole and the corners of the cell.

\section{The NuCleus.}

To the writer, at least, one of the most interesting phases of the subject was that pertaining to the behaviour of the nucleus in root-tips of certain Phanerogams. Tips of the primary roots of Zea Mays, Vicia Faba, Allium Cepa, and Phasechus vulgaris were used. Of these, Zea and Phaseolus proved to be most satisfactory.

The method of procedure was as follows. The seeds were allowed to germinate in moist sawdust, and when the primary root had reached a length of two or three centimetres the whole seedling of Zea was fastened by means of gypsum in a piece of glass tubing which had been widened out funnelwise at one end. The seedlings were placed in the funnel so that the root passed freely into the tube while the body of the seed remained in the widened part.

A thin batter of gypsum was now poured into the funnel so as to surround the seed but not to cover it entirely. The root was loosely wrapped with shreds of cotton close to the grain to prevent the gypsum batter flowing into the tube of the funnel. Fastened in this way, both root and shoot were left perfectly free, while the body of the seed was held secure and immovable so that not the slightest injury was received by the plant from the excessive weight of the seed during centrifugal action.

On account of the large size of the seed of Vicia, the whole seedling was not used. Root-tips about one centimetre long were cut off and inserted into tubes just large enough to admit them freely. The end of the root was then pushed a short distance into the gypsum batter which had been introduced into the end of the tube. The tip of the root thus rests in its own 
mould, and the pressure due to the increased weight is so evenly distributed that not even the cells of the cap itself sustain the least injury, except it be the outermost layer. The tubes and funnels are now packed into the cylinders previously mentioned, when all is ready for operation.

In order to observe the condition of the nucleus and the other cell-constituents just at the close of centrifugal action, tips of the roots were put at once into the fixing fluid (chromic-osmic-acetic acid). In order to observe the behaviour of cells at certain intervals subsequent to the action of centrifugal force, specimens of Zea remaining in the tubes were replaced in the sawdust or kept in a moist chamber. Of course, all tips cut from the plant previously to centrifugal action were fixed immediately on their removal from the centrifuge. The pieces of tissue were imbedded and sectioned. The sections were stained on the slide with safranin, gentian-violet, and orange G. By the method of preparing the tissue just outlined, the exact condition of all the protoplasmic constituents of the cell at the time of fixing is revealed in successful preparations with striking clearness.

As regards the cell-contents as a whole, we find here results similar to those already described; but, concerning the nucleus alone, phenomena are met with which merit special attention.

In certain cells of Zea, Vicia, and Phaseolus, not only do we find the contents of the nucleus displaced in its cavity as in the case of the cell, but the nucleolus may often be forced out through the nuclear membrane into the cytoplasm, when nucleus and nucleolus will be found lying some distance apart with all connexion between them severed. This shows quite clearly that the nucleolus is relatively much heavier than the other constituents of the nucleus.

Only one instance is known to the writer of any recorded observation upon this phase of the subject, namely that of Herrick ('95), referred to by Davenport ${ }^{1}$ ('97) in his Experimental Morphology. As stated by Davenport, Herrick found

\footnotetext{
${ }^{1}$ Herrick's paper was not accessible to me.
} 
that "when the ovary of a lobster is killed, the nucleoli of all the nuclei are found in contact with that part of the nuclear membrane which was the lowest at the moment of killing' (1. c., Fig. 22), and that 'the weight of the nucleolus is relatively so great as sometimes to cause a depression in the part of the nuclear membrane upon which it rests' (1. c., Fig. 23).

Strong centrifugal force reveals a series of phenomena relative to the specific gravity of the nucleolus, to which we shall now direct our attention.

In the smaller and densely filled embryonic cells of the root-tip, very little change is to be noticed; but farther back, where the cells have elongated somewhat, a marked difference is at once apparent. In those nuclei in which a displacement is plainly perceptible, the nucleolus lies in contact with that part of the membrane toward which the centrifugal force has been directed. (As in the case of the cell, this part will be spoken of as the lower side.) Not only the nucleolus, but much of the nuclear reticulum is displaced along with the former (Fig. I2). In cases like this the nucleolus, together with a portion of the threadwork, causes a decided depression in the nuclear membrane. To what extent the reticulum is pulled along by the heavy nucleolus cannot be stated with certainty.

From the displaced mass of reticulum there extend back to various points in the nuclear membrane many lininstrands (Fig. 12). That part of the nuclear membrane directly opposite the displaced mass to which these lininthreads extend is depressed or sunk in. In a great many nuclei presenting a similar orientation of their contents, a similar indentation is present. It is not, therefore, due to shrinkage, and the fact indicates strongly that the linin-thread at certain points is pretty firmly attached to the nuclear membrane.

The nucleolus is often only heavy enough to cause a slight depression at the lower side as in Fig. 12, but frequently this depression is augmented to a protuberance or beak equalling 
one-third to one-half the diameter of the nucleus before its membrane is ruptured and the nucleolus escapes into the cytoplasm. Sometimes the beak is drawn out into a long slender neck (Fig. I3). Such a condition is met with chiefly in the rapidly elongating cells of the central cylinder, but it may also happen in similar cells of the cortex. As a rule the nuclear membrane is ruptured sooner, so that only a short beak is formed. In the same section of a root-tip of $Z e a$, Phaseolus, and others, every conceivable transition between Figs. 12 and 13 may be seen in the plerome-cylinder.

It is, however, only when the cytoplasm offers a considerable resistance to the movement of the nucleus that the nucleolus can be made to fall through the membrane of the former. If the nucleus is able to move more freely within the cytoplasm, as is generally the case except in elongating cells of the plerome, it readily sinks to the lower end of the cell, resting against the end wall, when an expulsion of the nucleolus is impossible. In the rapidly elongating cells of the plerome the nucleoli seem to be larger and heavier than those in the adjacent region of the periblem.

The linin-reticulum, if containing only a relatively small quantity of chromatin, as in Fig. I3, will experience little or no displacement. As a rule, the reticulum or nuclear thread is displaced in a certain degree along with the nucleolus even in embryonic cells. The nucleolus is generally accompanied, when displaced, by the colourless area or sphere in which it often lies in the resting nucleus, a fact so noticeable in $Z$ ea. Sometimes, when the nucleolus is forced out of the nucleus as in Fig. I3, the former does not come into contact on all sides with the cytoplasm, but may lie within a colourless space.

Since the colourless fluid surrounding the nucleolus does not retain any stain, it cannot be said with certainty that it is carried along with the latter. The facts seem to indicate, moreover, that the specific gravity of this colourless sphere is greater than that of the remaining part of the nuclear sap, and that it may be of a more viscid nature. In Allium, and 
perhaps Vicia, the colourless area immediately surrounding the nuclcolus is less marked than in Zea. It is certainly not an artefact due to shrinkage.

The foregoing remarks pertain strictly to the nucleus in the so-called state of rest. A few statements may now be made concerning the same in process of division.

In the stage of the hollow spirem of the anaphase, the chromatin-thread in vegetative nuclei runs in tolerably regular turns along the nuclear membrane with an occasional turn or loop projecting into or traversing the nuclear cavity. As the nucleus here considered does not increase much in size above that of the resting-stage, the chromatin-spirem seems tolerably rigid, especially when we remember that in all probability it is fastened at certain points to the nuclear membrane by delicate threads of linin or of cytoplasm. Nevertheless, it often happens that even in smaller nuclei of embryonic cells a number of turns of the spirem fall toward the lower side of the nucleus.

During later stages of karyokinesis the elements of the mitotic figure are variously affected. The chromosomes when arranged in the equatorial plate are often less regularly oriented. The entire spindle, as in Tradescantia, falls to the bottom of the cell; and, if the normal position were oblique, it would not infrequently be bent and sometimes forced to lie transversely in the cell. No very striking effects were observed during later phases of mitosis, save some irregularity in the position of the chromosomes. The resulting daughtercells were often of unequal size, as in the case of the stamen hairs of Tradescantia.

Seedlings of $Z e a$, as already stated, were allowed to grow after the action of centrifugal force in order to observe the condition of the nucleus at subsequent intervals. It required only a short time to recover from the shock, for at the end of twenty-four hours the rate of growth in the primary root differed but little from that of control-specimens, being sometimes accelerated, sometimes retarded. Only few comparisons were made along this line as it was not my purpose to study 
the rate of growth as influenced by the action of centrifugal force.

Root-tips were fixed at subsequent intervals of six, eight, twenty, and twenty-four hours. In six or eight hours the displaced contents had become in a measure redistributed except in the long narrow cells of the plerome, and at the end of twenty or twenty-four hours no signs of a displacement were evident. But, if the nucleolus had been forced out of its nucleus, these two bodies were found lying separately in the cytoplasm, sometimes at considerable distances from each other. The nucleolus did not re-enter the nucleus even when a connexion remained between them as in Fig. I3. The enucleolated nuclei were often irregular in shape and not infrequently showed signs of disorganization.

All attempts to eject the nucleolus in cells of the various trichomes, \&c., proved futile. Either the resistance offered by the cytoplasm to the movement of the nucleus was too feeble, or the nucleolus was too light to admit of its ejection by means of the centrifugal force employed. Negative results were also obtained with trichomes from the leaves of Pinguicula, whose nuclei contain large crystals. Neither crystals nor nucleoli were ejected.

It was thought that sharp-pointed raphides of such plants as Agave mexicana might be made to pierce the cellulosemembrane. In Agave mexicana and others the raphides occur in cells containing mucilage, and, although the entire bundle is thrown into the end of the cell so that the sharp ends of the raphides touch the cell-membrane, yet in no case could they be seen to penetrate the wall in the least. After the operation the raphides moved back to their former position in the cell.

\section{CONCLUDING REMARKS.}

One of the great tasks of the physiologist, and perhaps that which overshadows all others in theoretical importance, is to know what cells can do under any and all conditions 
of life, and to understand the relation of these activities of the cell to each other and to the surrounding conditions. It does not matter whether these activities be of the so-called normal or abnormal kind; for who is prepared to say what is normal and what abnormal, and where the one leaves off and the other begins?

In this investigation centrifugal force was regarded largely as a stimulus, and the purpose constantly kept in view was to know what responses the living substance of the various cells would make to such a stimulus.

One of the most surprising phenomena, to the writer at least, is the great amount of what seemed to be severe treatment which many cells are able to endure. In Cladophora and various other Algae, where almost every visible trace of the living substance save the hautschicht (and the plasmic lamella in Cladophora) is crowded into a small compact mass in one end of the cell, and where three weeks or even a longer time is necessary to effect a redistribution of these contents similar to that existing under ordinary circumstances, not the slightest pathological phenomenon could be perceived in the vast majority of cases. Aside from the power of mere endurance in this respect, the factors that underlie the slow or rapid redistribution are still far from a satisfactory elucidation.

Of far greater interest, to the cytologist at least, are probably the principles underlying the various phenomena revealed in the types of cell-division which occur in Cladophora and Spirogyra. In the former not only does the formation of transverse cell-walls not stand in any direct connexion with nuclear division, but, so far as known, it is independent of the position or distribution of the nuclei. On the other hand, it is not improbable that further investigation will show that some direct relation does exist between the transverse septum in process of formation and the orientation of the nuclei. The process of the formation of a cell-wall in the cell-division of Spirogyra is in a measure transitional between the Cladophora type and that in which the cell-plate is laid 
down through the instrumentality of the connecting fibres. The peculiar cellulose-ring formed preparatory to cell-division in Oedogonium may be brought into the same category with Spirogyra and Cladophora, bearing perhaps a closer resemblance to the type of the former.

It is not easy to understand why in Cladophora the membrane once begun as a cellulose-ring is never brought to completion after a displacement of the cell-contents, without assuming that some very close relation exists between the nuclei and the origin of the transverse membrane, and that this relation having been once disturbed is never re-established. Since centrifugation never plasmolyzed the cells in question, the ectoplasm or hautschicht remained always in contact with the cellulose-ring, so that no mechanical injury could arise from that source. There are therefore strong grounds for the conclusion that in the Cladophora and Spirogyra types of cell-division a close relation exists between the nucleus or nuclei and the forming transverse membrane, and that, when such relation is once disturbed through a displacement of the nuclei in the cell by centrifugal force, it is never fully restored and the protoplast is incapable of completing the membrane.

It might be of interest in this connexion to know whether spiral or other secondary thickenings would develop further, if, at the beginning of the process, the contents of those cells were displaced in a similar manner.

Again, such cases as that illustrated in Fig. 3 present phenomena for which the writer is, as yet, unable to find a satisfactory explanation. It would seem at first that the size of the resulting cells might be proportional to the quantity of cytoplasm, and that that factor is the determining principle. Cell $\alpha$, Fig. 3, contains more chlorophyll and probably a greater number of nuclei than cell $b$, but whether the quantity of living substance apart from nuclei and chloroplasts is proportional to the sizes of the respective cells I am unable to say. It is more probable that the position of the division-wall is determined here also by 
the nuclei, and that the rôle of the cytoplasm is largely secondary.

The results obtained in root-tips of Zea, Allium, Vicia, and Phaseolus have thrown more light upon the specific gravity of various cell-constituents, and especially those of the nucleus. There is no doubt that the nucleolus is relatively a very heavy body, and that its specific gravity is greater in the nuclei of cells destined to a greater constructive activity. Cells of the plerome-cylinder, which eventually develop into the various thick-walled elements, demand a much greater constructive activity of their protoplasts than the smaller thin-walled cells of the cortex. The nucleus, which is beyond any doubt connected with the secretion of cell-wall substances, must do more work where thick-walled elements are produced and consequently it must have more food. From this fact and from what is known of the behaviour of the nucleolus during karyokinesis (Mottier, '97), the statement seems justified that the nucleolus represents so much food-material that may be drawn upon by the nucleus whenever necessity demands.

During the comparatively short time at my disposal, it was possible to do but little more than to give a general survey of a part of the field, covering a tolerably wide range among plants, and to indicate lines along which fruitful results might be expected. It was not possible under the circumstances even to make an exhaustive and quantitative study of a single phase of the various problems touched upon.

In an investigation of this kind nothing is more strikingly evident than the necessity of combining the best indirect methods of the histologist and cytologist with those of the physiologist.

It is hoped that some fact or suggestion contained in the foregoing may arouse a sympathetic interest in others having at their disposal the necessary mechanical apparatus for the prosecution of such and similar studies; for there is no doubt but that careful and painstaking investigation here will yield fruitful results. 
This work was carried out in the Botanical Institute at Leipzig, and I desire, in conclusion, to express publicly my indebtedness to Professor Pfeffer for his great kindness and constant advice throughout the entire work.

\section{LITERATURE.}

DavenPort, C. B., '97 : Experimental Morphology, Part I, i i 4, I897.

Dehnecke, C., ' 80 : Ueber nicht assimilirende Chlorophyllkörner, Inaug. Diss., Köln. Abstract in Bot. Ztg., xxxviii, 795-8. Also in Bot. Centralbl., i. 1537 .

Herrick, F. H., '95 : Movement of the Nucleolus through the Action of Gravity, Anat. Anz., x. 337-40, Jan: 8, 1895.

Klemm, P., '95: Desorganisationserscheinungen der Zelle, Jahrbiicher für wiss. Bot., xxviii, Heft 4, 2-74, I895.

Mottier, D. M., '97 : Beiträge zur Kenntniss der Kerntheilung in den Pollenmutterzellen einiger Dikotylen und Monokotylen, Jahrbücher für wiss. Bot., $\mathrm{xxx}$, Heft 2, 169-200.

Strasburger, E., '97: Botanisches Practicum, dritte umgearbeitete Auflage, p. $343, \mathrm{I} 897$. 


\title{
EXPLANATION OF FIGURES IN PLATE XVIII.
}

\author{
Illustrating Professor Mottier's paper on the Effect of Centrifugal Force \\ upon the Cell.
}

Fig. I. Cladophora. A cell drawn eighteen hours after the action of a centrifugal force of $1930 \mathrm{~g}$ for one hour and a half. The displaced contents have begun to distribute themselves; in the colourless part the plasmic lamellae are to be seen.

Figs. 2, 3. Cladophora. Both figures drawn two days after centrifugal action. In Fig. 2 cell-division had begun before the application of centrifugal force; the cellulose-ring, appearing in optical section as two inward projections on either side, never developed further as a transverse wall. In Fig. 3 a division of the cell has just taken place.

Figs. 4-6. Spirogyra. Centrifugal force, $1820 g$, duration three quarters of an hour. Fig. 4 was drawn immediately after centrifugal action at 5 p. m.; the two chlorophyll-bands, nucleus, and all cytoplasm capable of being displaced lie in a compact mass in the lower end of the cell. Relatively large starch-grains form a rosette about each pyrenoid.

Fig. 5. A cell larger than in Fig. 4, drawn at 9 a.m. the following morning; the primordial utricle is thicker, due to a redistribution of cytoplasm over the inner cell-surface. The bands with the nucleus have made some progress toward redistribution. Fig. 6 was drawn at a still later period.

Figs. 7-9. Cells from the stamen-hairs of Tradescantia virginica. Centrifugal force about $1820 g$, duration one hour.

Fig. 7. Karyokinetic figure at the close of the anaphase; each set of daughterchromosomes lies slightly inclined to the longitudinal axis of the cell. The beginning of the cell-plate is faintly visible; the vacuole occupies the upper end of the cell.

Fig. 8. Drawn twenty-two hours after centrifugal action; cell-division took place while the nucleus lay in the displaced position, thus giving rise to two daughtercells of greatly unequal size. The fact that the diameter of the nucleus of the smaller cell is almost as great as the length of the cell itself, seems to indicate that the cell was in process of division at the time of centrifugal action.

Fig. $9 a-g$ (semi-diagrammatic) represents a part of the process of cell-division in a cell in which the dividing nucleus and surrounding cytoplasm were displaced transversely. Observation began immediately after centrifugal action; $a$ to $f$ represents forty minutes, $f$ to $g$ eight minutes.

Figs. Io, II. Cells of the leaf of Funaria. Centrifugal force 1700 to $1820 \mathrm{~g}$, duration one hour and a half.

Fig. Io. A cell from basal half of leaf showing displaced contents.

Fig. II. Displacement in a cell which had been first plasmolyzed.

Fig. 12. Nucleus from a cell of the plerome of a root-tip of Allium. From the displaced mass of nuclear thread, strands extend to various points in the nuclear membrane, especially to the sunken-in part opposite. The nucleolus was on the point of breaking through the nuclear membrane.

Fig. I3. Part of a long cell from the plerome of a root of Zea Mays. The heavy nucleolus has drawn a part of the nuclear membrane out into a long ncck. Starch grains and other inclusions lie in the lower end of the cell. 


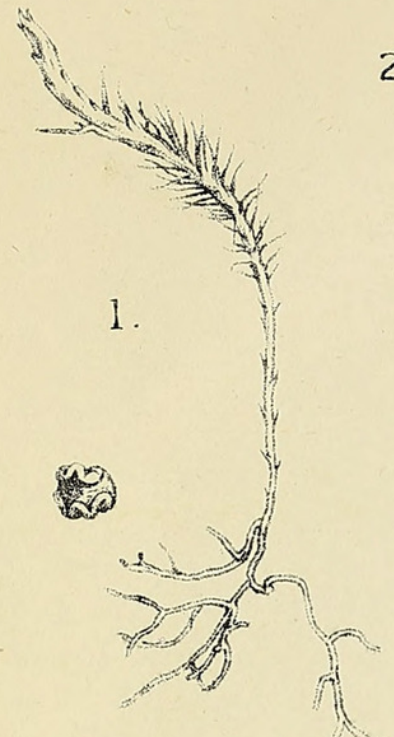

2.
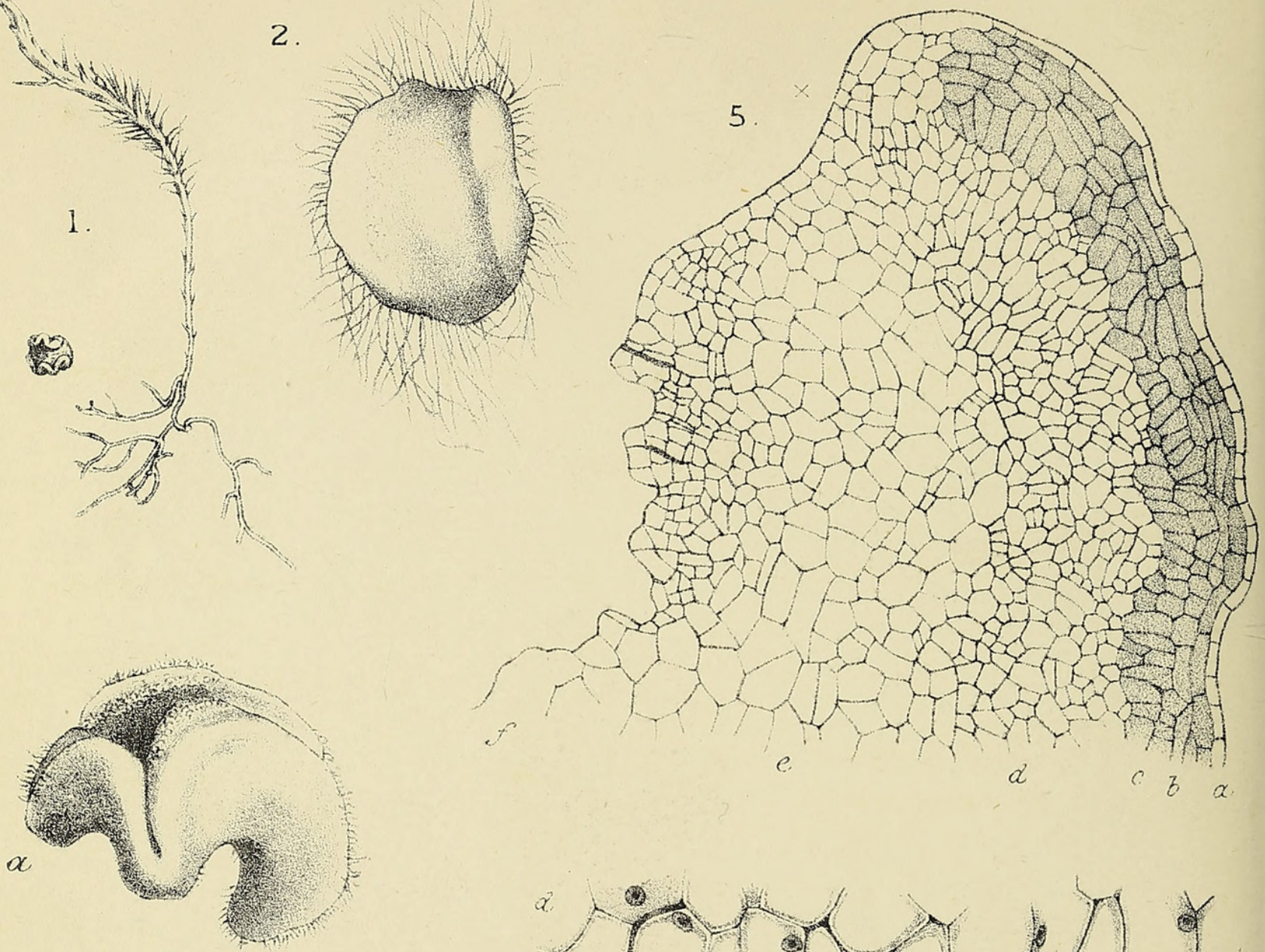

3
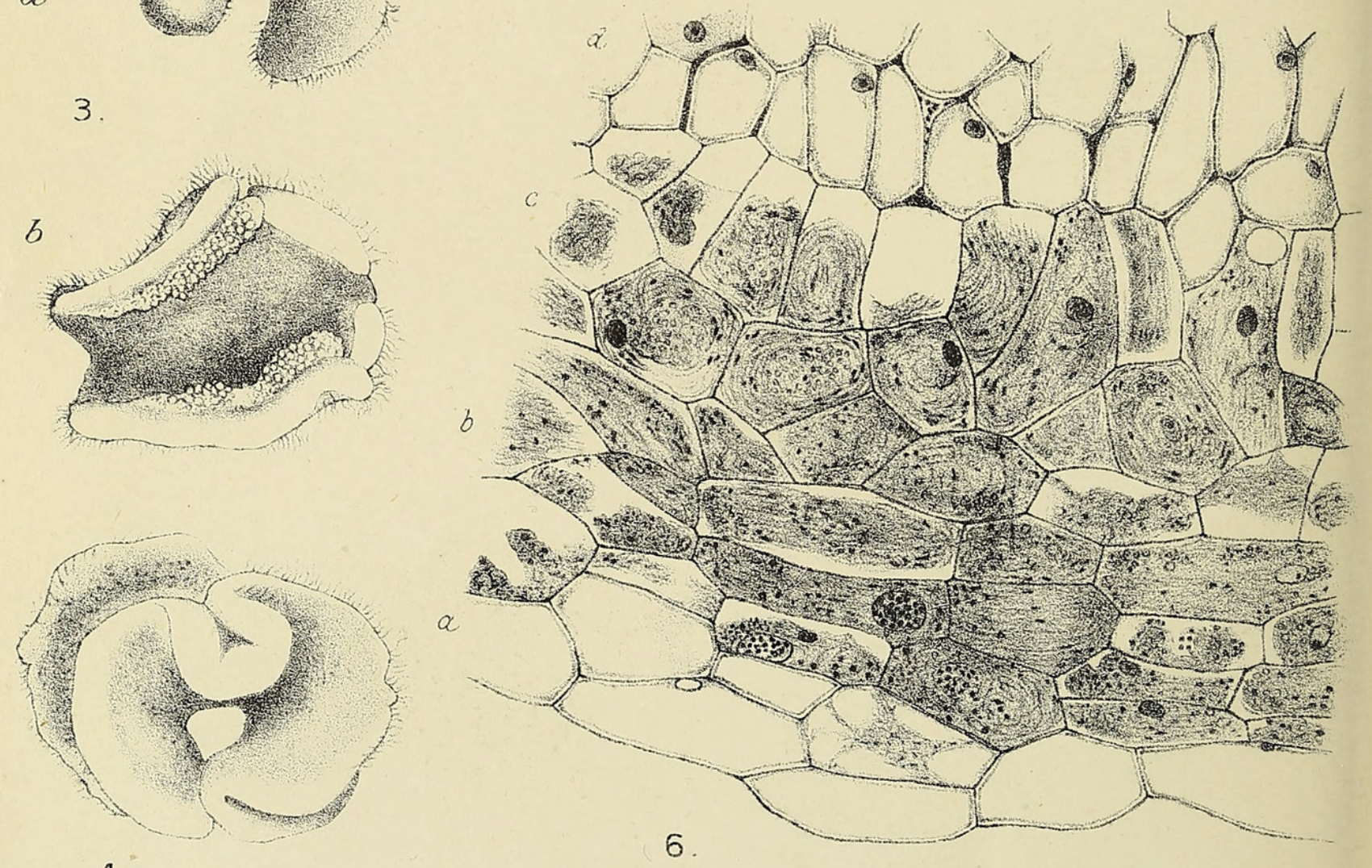

4

W.H.Lang del.

LANG.- LYCOPODIUM CLAVATUM. 


\section{$2 \mathrm{BHL}$ Biodiversity Heritage Library}

Mottier, David M . 1899. "The effect of centrifugal force upon the cell." Annals of botany 13, 325-361. https://doi.org/10.1093/oxfordjournals.aob.a088736.

View This Item Online: https://www.biodiversitylibrary.org/item/232524

DOI: https://doi.org/10.1093/oxfordjournals.aob.a088736

Permalink: https://www.biodiversitylibrary.org/partpdf/318542

\section{Holding Institution}

Smithsonian Libraries

\section{Sponsored by}

Biodiversity Heritage Library

\section{Copyright \& Reuse}

Copyright Status: Not in copyright. The BHL knows of no copyright restrictions on this item.

This document was created from content at the Biodiversity Heritage Library, the world's largest open access digital library for biodiversity literature and archives. Visit BHL at https://www.biodiversitylibrary.org. 